\title{
Influences of predators and conspecifics on recruitment of a tropical and a temperate reef fish
}

\author{
Mark A. Steele ${ }^{1, *}$, Graham E. Forrester ${ }^{1}$, Glenn R. Almany $^{2}$ \\ ${ }^{1}$ Department of Biology, UCLA, 621 Circle Drive South, Box 951606, Los Angeles, California 90095-1606, USA \\ ${ }^{2}$ Department of Zoology, Oregon State University, 3029 Cordley Hall, Corvallis, Oregon 97331, USA
}

\begin{abstract}
An active debate has focused on whether patterns in the abundance of reef fishes are primarily determined by the supply of larvae or by subsequent interactions occurring on the reef. By manipulating the presence of predators and the density of older conspecifics on small standardized reefs, we tested the influences of these 2 factors - and interactions between them - on recruitment of reef fishes. To assess the generality of our findings, we conducted similar experiments on 2 closely related species in 2 different systems: 1 tropical and 1 temperate. At Santa Catalina Island (a temperate site in southern California, USA) we worked with the blackeye goby Coryphopterus nicholsii and at Lee Stocking Island (a tropical site in the Bahamas) we studied the bridled goby Coryphopterus glaucofraenum. Predators reduced recruitment of blackeye gobies, but in contrast, in one experiment, recruitment of bridled gobies was positively affected by 1 class of predators (reef residents) and unaffected by transient predators. In another experiment, Iecruitment of bridled gobies was unaffected by either class of predators; however, there was little statistical power to detect a similar positive effect of predators. Older conspecifics (adults and subadults) did not significantly influence recruitment of blackeye gobies, but recruitment of bridled gobies was negatively related to density of adult conspecifics. For both species, the presence of predators did not influence the relationship between recruitment and the density of older conspecifics. Our results suggest that patterns of abundance among local populations of reef fishes can be decoupled from patterns of larval supply by reef-based biotic processes (namely predation and intraspecific interactions). However, the influences of older conspecifics and predators varied widely between the 2 quite similar species that we studied. This underscores the need to understand the specific reasons for such differences in order to make predictions regarding the relative importance of these processes in novel circumstances
\end{abstract}

KEY WORDS: Reef fishes - Recruitment - Predation - Density dependence Gobies

\section{INTRODUCTION}

In open populations, local reproductive output may have little or no influence on input ('births') to these same populations. 'Openness' is a consequence of a life history that includes 1 or more dispersive stages, such that input to any local population may come from any number of other populations. This life-style and population structure characterizes the majority of marine organisms, as well as many aquatic and terrestrial species, and poses unique problems for population biologists, primarily because local 'birth' rates cannot

\footnotetext{
•E-mail:masteele@ucla.edu
}

be predicted from local fecundity. In closed populations, it is only necessary to understand the processes that affect the fecundity of members of the population in order to predict birth rates. But in open populations, it is also necessary to understand processes that influence individuals during dispersal and that affect the likelihood that an individual will take up residence in a particular local population

This 'taking-up of residence' is often called recruitment. An inexact term, recruitment has been used to mean many different things by many different researchers. Here, we use it in an operational sense: the addition of individuals to a population measured at some point in time after they have entered the population. Recruitment, then, encompasses 2 critical periods: 
the brief moment in time when a dispersing individual joins more sedentary individuals (settlement), and the period between settlement and the time when a researcher observes the new 'recruit'. As a result, answers to questions about the importance of recruitment may depend on the length of time between settlement and the censusing of recruits.

When processes acting after recruitment do not modify patterns established at recruitment, it is necessary only to understand the processes that generate variation in recruitment in order to predict patterns of variation in older stages in and among open local populations. There have been a number of studies (e.g. Doherty 1981, 1982, 1983, Victor 1983, 1986, Doherty \& Fowler 1994) that indicate that patterns in recruitment are not strongly modified by post-settlement interactions. Therefore, understanding the causes of variation in recruitment may be crucial for predicting patterns in abundance of older benthic and demersal stages. A host of factors are known to generate variation in recruitment of reef fishes, including microhabitat (Sale et al. 1984, Shulman 1984, 1985, Carr 1989, 1991, 1994, Levin 1993, Caselle \& Warner 1996, Schmitt \& Holbrook 1996), resident conspecifics (Sale 1976, Sweatman 1985, Behrents 1987, Booth 1992, Forrester 1995, Tupper \& Boutilier 1995, Schmitt \& Holbrook 1996, Steele 1997), potential interspecific competitors (Shulman et al. 1983. Sweatman 1985, Jones 1987, Sweatman \& St. John 1990), and predators (Doherty \& Sale 1985, Beets 1997, Steele 1997). However, it is difficult to generalize about the importance of each of these processes for 2 important reasons: (1) past studies have used a variety of experimental methodologies, which precludes direct comparisons among them; and (2) each process is often explored independently, precluding detection of interactions among processes and making it impossible to assess the relative importance of each process (Underwood \& Petraitis 1994, Steele 1997).

In this study, we investigated 2 potential sources of variation in recruitment of reef fishes - predation and density-dependent influences of older conspecifics and we did this using 2 closely related species in 2 very different systems: 1 temperate and 1 tropical. Our experimental design allowed us to test for interactions among the 2 processes investigated; and by using the same experimental design for the 2 species, we were able to assess the generality of our findings.

\section{METHODS}

Systems studied. We conducted our experiments on 2 species in the family Gobiidae. At Santa Catalina Island $\left(33^{\circ} 27^{\prime} \mathrm{N}, 118^{\circ} 29^{\prime} \mathrm{W}\right), 33 \mathrm{~km}$ off the coast of southern California, we studied the blackeye goby
Coryphopterus nicholsii, and on the Great Bahama Bank, near Lee Stocking Island $\left(23^{\circ} 46^{\prime} \mathrm{N}, 76^{\circ} 10^{\prime} \mathrm{W}\right)$ in the Bahamas, we studied the bridled goby Coryphopterus glaucofraenum. Both species are small ( $\sim 50$ and $90 \mathrm{~mm}$ maximum standard length [SL] for bridled and blackeye gobies, respectively), benthic, and fairly sedentary, maintaining territories no greater than a few square meters. The 2 gobies are very common and on natural reefs reach densities of up to 20 and $30 \mathrm{~m}^{-2}$ for blackeye and bridled gobies, respectively (Forrester 1995 , Steele 1997). Both species feed on invertebrates: the blackeye goby eats both zooplankton and benthic invertebrates (Wiley 1973, Steele unpubl.), while the bridled goby feeds almost exclusively on benthic invertebrates (Forrester unpubl.).

Both species are protogynous hermaphrodites (Cole 1983, Cole \& Shapiro 1992) and males guard nests of demersal eggs. After hatching, larval bridled gobies spend approximately 1 mo in the plankton (Sponaugle \& Cowan 1994), while blackeye gobies are planktonic for 2 to 3 mo before settling to adult habitat (Steele unpubl.). At settlement, blackeye gobies are 15 to $25 \mathrm{~mm}$ SL (Steele pers. cbs.) and bridled gobies are 7 to $9 \mathrm{~mm}$ SL (Forrester \& Steele pers. obs.). Sexual maturity can be reached rapidly, in as little as 2 mo post-settlement in bridled gobies (at a minimum size of $16 \mathrm{~mm}$ SL; Cole \& Shapiro 1992) and in 3 mo in blackeye gobies (at $\sim 5 \mathrm{~mm} \mathrm{SL}$; Wiley 1973).

At Santa Catalina Island, blackeye gobies are primarily preyed upon by the kelp bass paralabrax clathratus (family Serranidae). This species comprises about $90 \%$ of all piscivorous fishes at Santa Catalina (Steele unpubl.) and it actively hunts blackeye gobies. In some sandy areas, such as the site where we conducted our experiments, another serranid, the barred sand bass Paralabrax nebulifer, may also be an important predator Over the course of a day, both predatory serranids move at least 10 s to 100 s of meters, so at the scale of the small reefs used in this study, these 2 predators are transient visitors. In fact, in this system, there are no piscivorous predators that are so sedentary that they could be considered residents on small patch reefs like those used in this study.

In the Bahamas, however, the suite of predators that may consume bridled gobies is much more diverse, both in terms of species diversity and in terms of movement and foraging patterns. On isolated patch reefs like those used in this study, piscivorous predators can be divided into 2 types: resident predators, which are very sedentary and do not move among reefs, and transient predators, which do. Resident predators include serranids ( 3 common species), moray eels (Muraenidae; 2 species), and squirrelfish (Holocentridae ${ }_{i} 2$ species), while the numerically dominant transient predator is a jack (Carangidae). 
Experiments. To test for effects of predators and older resident conspecifics, we manipulated the presence of predators (with cages) and the density of conspecifics in a factorial design. Our goal was to determine the nature of the relationship between recruitment and the density of older conspecifics (subadults and adults), so rather than use few levels of density with replication (an ANOVA approach), we used many (8) levels of density with no replication (a regression approach). Densities of the older gobies used in the experiments spanned those naturally encountered for those size/age classes, ranging from 2 to $15 \mathrm{~m}^{-2}$ in blackeye gobies and from 0.8 to $13.1 \mathrm{~m}^{-2}$ in bridled gobies. In a second experiment with bridled gobies, we also used a portion of the design described above - we manipulated the presence of predators, without manipulating the density of adult conspecifics. We took advantage of natural variation in adult density to test for relationships between recruitment and adult density, and interactions between adult density and predator exposure.

The experiments were conducted on small isolated patch reefs that were constructed of natural materials. For blackeye gobies at Santa Catalina, we used $1 \mathrm{~m}^{2}$ rock rubble reefs; and for bridled gobies at Lee Stocking, we used $5.1 \mathrm{~m}^{2}$ reefs built of live coral (see Hixon \& Carr 1997 for details on construction and composition of the coral reefs). The reefs were constructed on sand flats and were separated by open expanses of sand $(10 \mathrm{~m}$ between reefs at Santa Catalina, $200 \mathrm{~m}$ between reefs at Lee Stockingl to minimize migration of gobies among reefs. Rocks and coral were placed on mats of plastic mesh to keep them from sinking into the sand.

Santa Catalina Island experiments: At Santa Catalina, we used 2 predator treatments: predators present (uncaged reefs) and predators absent (caged reefs). We used $1 \times 1 \times 0.67 \mathrm{~m}$ high cages of rigid black plastic netting $(19 \mathrm{~mm}$ mesh, $2 \mathrm{~mm}$ thick polyethylene plastic) on polyvinyl chloride (PVC) pipe (25 mm outer diameter) frames. In the context of another experiment (described in Steele 1997), we tested for artifacts of these cages on recruitment of blackeye gobies. To test for artifacts, we compared the number of blackeye goby recruits accumulated over $25 \mathrm{~d}$ on rock-rubble patch reefs inside partial cages (cages lacking one-half of 1 side) ( $n=15$ ) with the number of recruits accumulated on uncaged reefs $(n=6)$. We expected there to be no difference in recruitment between the 2 treatments if there were no cage artifacts.

To test for effects of predators and older conspecifics on blackeye gobies, we conducted 2 experiments, identical in design, at Santa Catalina in 1996 (13 July to 14 August and 22 October to 19 December). A second experiment was conducted because, in the first ex- periment, loss of older conspecifics stocked on predator-exposed reefs was very high over the first day of the experiment. As a result, there was a relatively small range of densities of conspecifics on predatorexposed reefs ( 0 to 6.6 vs 2 to $14 \mathrm{~m}^{-2}$ on predator-free reefs), which precluded a strong test of the influence of older conspecifics on recruitment in the presence of predators. We circumvented this problem in the second experiment by caging the 'predator-exposed' reefs for $1 \mathrm{~d}$ to allow the stocked fish a chance to establish themselves on the reefs before removing the cages and exposing them to predators. Consequently, in the second experiment, there were similar ranges of adult densities on predator-exposed and predator-free reefs: 2 to 11.9 and 2 to $13.7 \mathrm{~m}^{-2}$, respectively.

In the experiments at Santa Catalina Island, recruitment was measured as the number of individuals that had settled from the plankton and then survived on the reefs until collected 26 to 32 d later. Visual censuses of recently settled blackeye gobies are not very accurate (Steele unpubl.), so we used the number of recruits collected by scuba divers using handnets and the anesthetic quinaldine as our measure of recruitment (in the second experiment, which lasted $58 \mathrm{~d}$, recruits were collected twice, once after $32 \mathrm{~d}$ and again after another $26 \mathrm{~d}$ ). Counts of older (and hence larger) fishes were quite accurate, and these were made 4 to 11 times during each of the 3 , month-long periods of the 2 main experiments. Also, the number of piscivorous fishes (kelp bass and barred sand bass) within $1 \mathrm{~m}$ of each reef was recorded during the periods when gobies were counted.

The older gobies stocked on the reefs were all tagged subcutaneously with plastic implant tags ( $1 \times$ $2.5 \mathrm{~mm}$ ) with alphanumeric codes that allowed us to distinguish each individual and to distinguish stocked residents from recruits (which settled from the plankton) and immigrants (from nearby natural reefs), which were rare. In the July-August experiment with blackeye gobies, we stocked subadults that ranged from 35 to $45 \mathrm{~mm} \mathrm{SL}$. By the end of the experiment (1 mo later), based on their size ( 41 to $52 \mathrm{~mm} \mathrm{SL}$, mean $=46.6 \mathrm{~mm}$ ), most of the surviving residents were sexually mature. In the October-December experiment we used subadults and adults, ranging from 40 to $50 \mathrm{~mm} \mathrm{SL}$, which, by the end of the first month, were all large enough (46 to $60 \mathrm{~mm} \mathrm{SL}$, mean $=52.1 \mathrm{~mm}$ ) to be sexually mature.

The experimental reefs were built in a $2 \times 8$ grid in water 9 to $13 \mathrm{~m}$ deep. Cages, placed on half of the reefs, were assigned systematically - alternating with uncaged reefs within and between the 2 rows of 8 reefs. Density treatments were assigned randomly within the 2 predator treatments.

In testing for effects of older blackeye gobies on recruitment, it was not appropriate to use the initial 
density of blackeye gobies stocked on the reefs as the measure of density because these densities changed over time as fish died or left the reefs. We therefore used our 4 to 11 visual censuses to calculate the average density of older, tagged conspecifics on each reef over the course of each experiment and we used this as our measure of density of older blackeye gobies. This approach is more realistic biologically than using the density initially stocked, but it is not completely accurate. If the density of residents on a reef changes over the course of an experiment, then fish that settle near the beginning of the experiment will be exposed to a different density of adults than those that settle near the end. In the second experiment with blackeye gobies (which ran for $58 \mathrm{~d}$ ), to minimize the mismatch between actual densities of older conspecifics that settlers encountered and our estimate of conspecific density, recruitment was measured during 2 periods (32 and $26 \mathrm{~d}$ ) rather than one $58 \mathrm{~d}$ period. The influences of density of older conspecifics and predators were then evaluated (see 'Statistical analyses' for details) separately for the 2 periods, using time-averaged densities of older conspecifics for each period.

Lee Stocking Island experiments: Two experiments were conducted at Lee Stocking Island and these differed from the Santa Catalina Island experiments in a few ways, the foremost being the use of additional predator-exposure treatments. Some of the predator species in the Bahamas are very sedentary and do not move among the small isolated reefs we used. We were able to manipulate the presence of these resident predators by removal (see Hixon \& Carr 1997 for details). However, the more mobile predator species could not be manipulated by removal, so we manipulated their presence with cages. Because the 2 classes of predators (resident and transient) hunt prey in different ways (Hixon \& Carr 1997), which may cause them to have different effects on their prey, we explored the effects of each class of predators on the bridled goby. We used 4 orthogonal predator treatments: no predators (caged reefs with resident predators removed: $-\mathrm{R}-\mathrm{T}$ ); resident predators only (caged reefs with resident predators present: $+R-T$ ); transient predators only (uncaged reefs with resident predators removed: $-\mathrm{R}+\mathrm{T}$ ); and all predators present (uncaged reefs with resident predators present: $+R+T$ ). Hence, a subset of 2 of the 4 predator treatments (all predators absent and all predators present) had the equivalent predator treatments as in the experiments at Santa Catalina Island. $+\mathrm{R}$ reefs had densities of resident predators that were equivalent to those on naturally occurring patch reefs (Hixon \& Carr 1997). The 2 experiments at Lee Stocking Island were both conducted on the same array of reefs, at 3 to $5 \mathrm{~m}$ depth, and treatments (described below) were assigned randomly to reefs.
At Lee Stocking, transient predators were excluded with large cylindrical cages, $6 \mathrm{~m}$ in diameter and $4.5 \mathrm{~m}$ high, which were buoyed at the top, so they reached the water's surface. These cages were constructed of tar-coated knotless nylon cloth netting, with $9.5 \mathrm{~mm}$ mesh (which settling gobies can easily pass through). As part of the first experiment (hereafter referred to as the 1995 experiment), which lasted 32 d during August and September 1995, we tested for artifacts of caging by comparing recruitment of bridled gobies on uncaged reefs with that on partially caged reefs ('cage controls') ( $n=6)$. Both partially caged and uncaged reefs had natural densities of resident predators and were exposed to transient predators $(+R+T)$. Partial cages had the same dimensions as complete cages, but were formed of 4 panels of netting buoyed to the surface, alternating with open areas of equal width.

In the 1995 experiment, we manipulated predator exposure, but did not manipulate the density of adult bridled gobies. However, since there was considerable natural variation in the density of adult gobies on the experimental reefs, we were able to test for relationships between recruitment and adult density. In this experiment, presence/absence of resident and transient predators was manipulated orthogonally, resulting in 4 treatment combinations $\left(+R+T_{1}+R-T_{1}-R+T\right.$, and $-R-T$ ), and there was the additional partial-cage treatment ( $\mathrm{n}=6$ for each treatment). The partial cage treatment was also $+\mathrm{R}+\mathrm{T}$, and since we detected no cage artifacts (see 'Results'), this treatment was pooled with the uncaged $+R+T$ treatment.

Bridled gobies can be can be counted quite accurately during underwater visual censuses (Forrester unpubl.); so in this experiment we estimated recruitment as the number of bridled gobies $<12 \mathrm{~mm} \mathrm{SL}$ counted by 1 diver (G. Forrester), on each reef, at the end of the experiment. Bridled gobies of this size are less than about 3 wk age post-settlement (Sponaugle \& Cowan 1994, Steele \& Forrester unpubl.). Density of adults was also estimated visually at the same time (by the same diver) and individuals $>25 \mathrm{~mm}$ SL were counted as adults. We assume that this one-time, snapshot estimate of adult density actually reflects the densities of adults that were present on the reefs during the period when the $<12 \mathrm{~mm}$ long bridled gobies were recruiting to the reefs. Since adult densities were estimated only at the end of this experiment, we cannot directly evaluate this assumption; however, in the second experiment at Lee Stocking Island (described below) adult densities were visually estimated twice, at a $2 \mathrm{wk}$ interval. These 2 measures of adult density were highly correlated ( $\mathrm{r}=0.92, \mathrm{p}<$ $0.000001, n=32$ ), indicating that our assumption of little change in adult density over the $3 \mathrm{wk}$ recruitment period is reasonable. 
In the second experiment (which lasted $15 \mathrm{~d}$ during July and August 1996; hereafter referred to as the 1996 experiment), we manipulated predator exposure (4 combinations: $+\mathrm{R}+\mathrm{T},+\mathrm{R}-\mathrm{T},-\mathrm{R}+\mathrm{T}$, and $-\mathrm{R}-\mathrm{T}$ ) and crossed this with 8 levels of density of adult bridled gobies. These adults ranged from 28 to $46 \mathrm{~mm} \mathrm{SL}$ and were not tagged. By virtue of their size, the adults were easily distinguished from the much smaller $<<12 \mathrm{~mm}$ SL) recruits that accumulated during the experiment. On each reef, bridled gobies (recruits, <12 mm SL, and adults, $>25 \mathrm{~mm} \mathrm{SL}$ ) were visually censused by 1 diver (G. Almany), $15 \mathrm{~d}$ after the initiation of the experiment. We used these counts as our measure of recruitment during the experiment, and adult density was estimated as the average of the density stocked on the reefs and the density counted on Day 15.

Statistical analyses. We aimed to address 3 main questions: (1) Is recruitment affected by predators? (2) Is recruitment affected by the density of older conspecifics? (3) Do effects of conspecific density and predation interact? Statistically, these questions were evaluated with analysis of covariance (ANCOVA). The ANCOVAs for the blackeye goby at Santa Catalina Island included 2 factors: predator treatment (a categorical variable), and density of older conspecifics (a continuous variable i.e. a covariate). The predator treatment term tests for an effect of predators on recruitment, and the conspecific density term tests for a linear, density-dependent effect of older conspecifics on recruitment. The interaction term between the 2 main effects tests for a statistical interaction between the 2 processes. Formally, the interaction term tests for homogeneity of slopes-and if the slopes are not homogeneous, then a test of the 2 main effects cannot be made. Additionally, when the slopes are homogeneous (i.e. $p>0.05$ for the interaction term), the interaction term must be eliminated from the statistical model before a test and estimate of the 2 main effects can be made (Wilkinson et al. 1992).

The ANCOVAs for the bridled goby at Lee Stocking Island included 3 factors: presence/absence of resident predators (categorical), presence/absence of transient predators (categorical), and density of adult bridled gobies (continuous). All possible interactions between these 3 main effects were initially included in the models for each experiment, and then, interactions with the covariate were sequentially eliminated (starting with the highest-order interaction) from the models if nonsignificant $(p>0.05)$.

For all models, parametric assumptions of ANCOVA (normality and homoscedasticity) were evaluated visually with normal-probability plots and regressions of residuals versus estimates. Transformation to squareroot $(x+0.5)$ provided an acceptable fit to both assumptions for blackeye gobies. The same transfor- mation improved the skewed distribution (caused by many zeros) of bridled goby data for both experiments, but these data still violated the assumption of normality. We proceeded with ANCOVA for this species anyway, since ANCOVA is robust to violations of the assumption of normality, but statistical results for the bridled goby should be interpreted cautiously.

When nonsignificant results occurred in both experiments on a species, we took the consistency in the results to indicate that there were really no effects of the treatments. In 2 cases, an effect of predators or density was detected in 1 experiment, but not detected in the second experiment on the same species. In these cases we used power analyses (following Cohen 1988) to determine whether the lack of agreement between experiments reflected a real biological difference, or merely the inability to detect a treatment effect in the nonsignificant experiment because of low test power.

\section{RESULTS}

\section{Tests for cage artifacts}

The cages used to manipulate predator exposure appeared to cause no major artifacts on recruitment of the 2 goby species, indicating that we can reasonably ascribe differences between caged and uncaged plots to effects of predators. Recruitment of blackeye gobies did not differ significantly between partially caged reefs and uncaged reefs: mean $\pm 1 \mathrm{SE}=1.7 \pm 0.5$ versus $1.9 \pm 0.5$ recruits reef ${ }^{-1}(\mathrm{n}=15$ and 6 , respectively), independent $t$-test, $t=0.2$, $\mathrm{df}=19, \mathrm{p}=0.8$. Likewise, there was no significant difference in recruitment of bridled gobies between partially caged and uncaged reefs: $4.2 \pm 1.5$ versus $5.2 \pm 1.5$ recruits reef ${ }^{-1}$, respectively, $\mathrm{n}=6$ (independent $t$-test: $t=0.5, \mathrm{df}=10, \mathrm{p}=0.6$ ).

\section{Blackeye goby}

Recruitment of blackeye gobies was not influenced by the density of older conspecifics during either experiment (Fig. 1, Table 1). Predators, however, did reduce recruitment of blackeye gobies by 37 to $74 \%$ relative to predator-free reefs during the 3 month-long periods of the 2 experiments (Fig. 2). This effect of predators was always at or near the level of statistical significance (Table 1). Predators, however, did not alter the (lack of a) relationship between recruitment and density of older conspecifics (Fig. 1), as indicated by nonsignificant interactions between the effects of older conspecifics and the effects of predators (Table 1) 
a) First Experiment: July-August

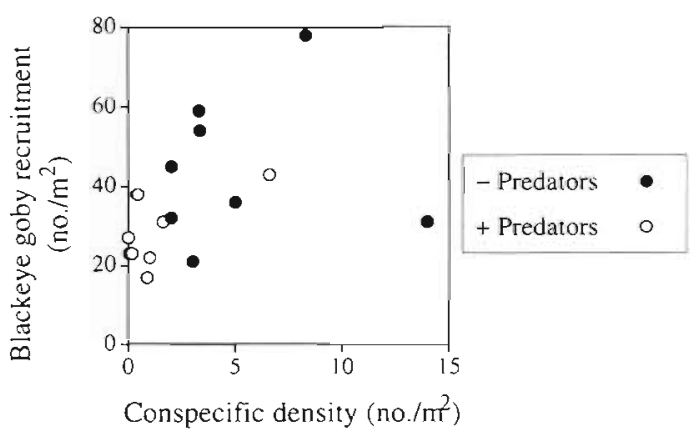

Second Experiment:

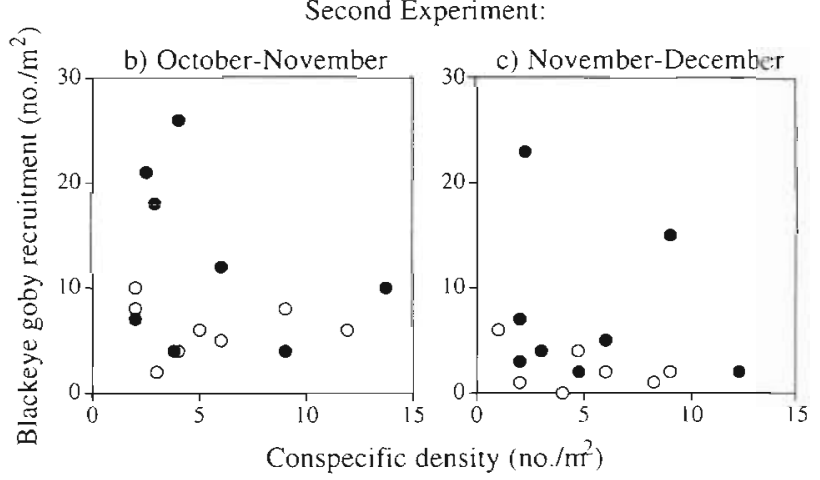

Fig. 1 Relationships between recruitment of blackeye gobies and the density of older, tagged blackeye gobies present on experimental reefs, in the presence $(n=8)$ and absence $(n=8)$ of predators. Data are shown for both experiments with blackeye gobies and for each month-long period of the second experiment

Table 1. Summary of results from ANCOVA testing for effects of predators, density of older conspecifics, and interactions between these 2 factors on recruitment of blackeye gobies. Tests for main effects (effects of predators and conspecifics) were made after eliminating the nonsignificant $(p>0.05$ ) interaction term from the models (note $\mathrm{df}_{\text {; }}$ see 'Methods: statistical analyses' for rationalel. Recruitment was transformed to square-root $(x+0.5)$ to improve the normality of the data

\begin{tabular}{|lccl|}
\hline Source & df & $F$ & $p$ \\
\hline Expt 1 (July-August) & & & \\
Older conspecifics & 1,12 & 0.52 & 0.49 \\
Predators & 1,13 & 7.46 & 0.017 \\
Predators $\times$ Older conspecifics & 1,11 & 0.20 & 0.66 \\
Expt 2, period 1 (October-November) & & \\
Older conspecifics & 1,13 & 0.55 & 0.47 \\
Predators & 1,13 & 3.74 & 0.075 \\
Predators $\times$ Older conspecifics & 1,12 & 0.77 & 0.40 \\
Expt 2, period 2 (November-December) & & \\
Older conspecifics & 1,12 & 0.39 & 0.54 \\
Predators & 1.12 & 6.23 & 0.028 \\
Predators $\times$ Older conspecifics & 1,11 & 0.02 & 0.90 \\
\hline
\end{tabular}

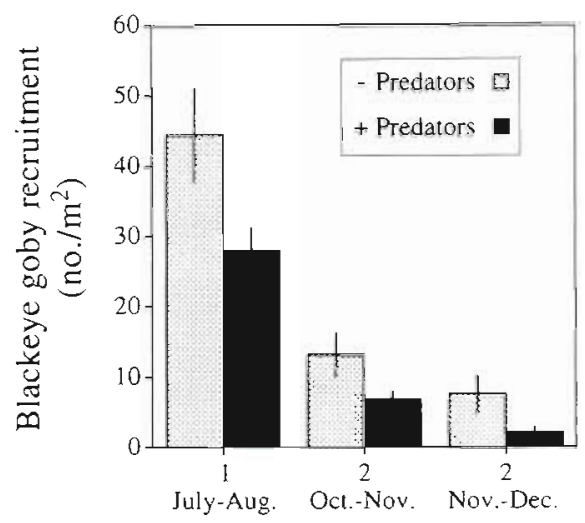

Experiment

Fig. 2. Influences of predators on recruitment of blackeye gobies. Data are means $\pm 1 \mathrm{SE}, \mathrm{n}=8$ for each bar. Differences between predation treatments were at or near the level of statistical. significance in all 3 cases (see Table 1)

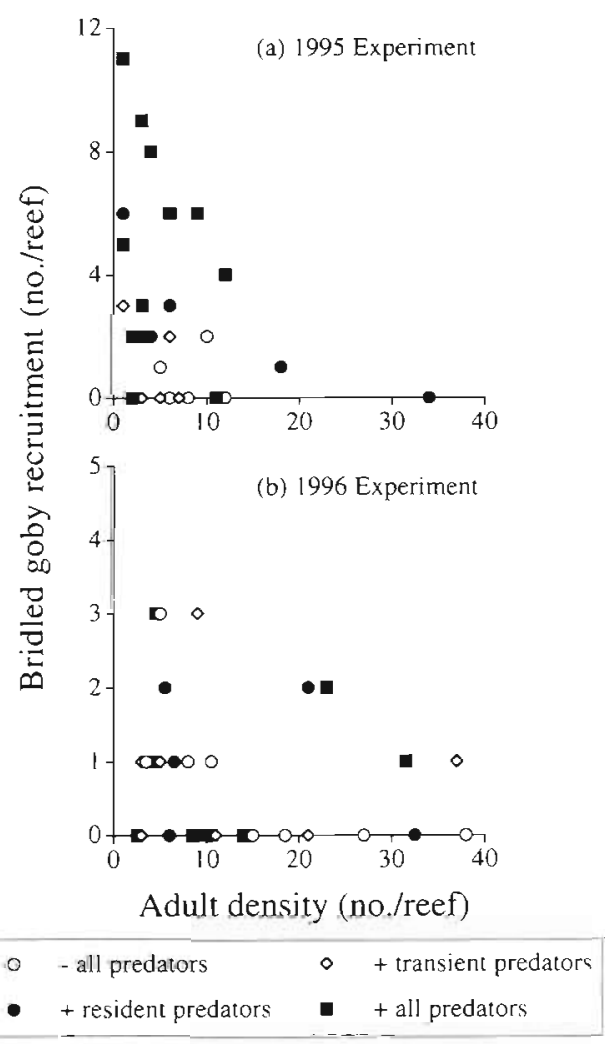

Fig. 3. Relationships between recruitment of bridled gobies and the density of adult bridled gobies, in 4 predator-exposure treatments during the $1995(n=6$ for each predation treatment, except for the $+R+T$ treatment where $n=12$ ) and 1996 ( $\mathrm{n}=8$ for each predation treatment) experiments. Recruitment was significantly negatively related to adult density in the 1995 experiment, but not in the 1996 experiment (see Table 2) 


\section{Bridled goby}

In the 1995 experiment, recruitment of bridled gobies was negatively related to the density of adults (Fig. 3, Table 2), although several reefs (10 of 30 ) over the range of adult densities received no recruits. In the 1996 experiment there was no statistically significant relationship between recruitment and adult density (Table 2), although there was a similar tendency for recruitment to decline as density of adults increased (Fig. 3). Recruitment during the 1996 experiment was much lower than in the 1995 experiment (1995: range = 0 to 11 recruits/reef, mean $\pm 1 S E=2.7 \pm 0.5 ; 1996$ : range $=0$ to 3 recruits $/$ reef, mean $=0.75 \pm 0.2$ ), and during the 1996 experiment, 17 of 32 reefs received no recruits. Power analysis indicated that we were unlikely to have detected a negative relationship between adult density and recruitment in 1996 of the strength that was observed in 1995 (power $=0.28$, assuming that the relationship with density explained the same proportion [0.19] of the total variance in recruitment as it did in 1995, and $p=0.05$ ). We conclude, therefore, that recruitment in bridled gobies declines with increasing adult density, but that low recruitment in 1996 made the relationship difficult to detect in that year.

Recruitment of bridled gobies was strongly affected by resident predators during the 1995 experiment (Table 2); the effect, however, was positive (Fig. 4), not negative as would be expected if the primary effect of the predators were due to consumption of recently settled gobies. No similar positive effect of resident

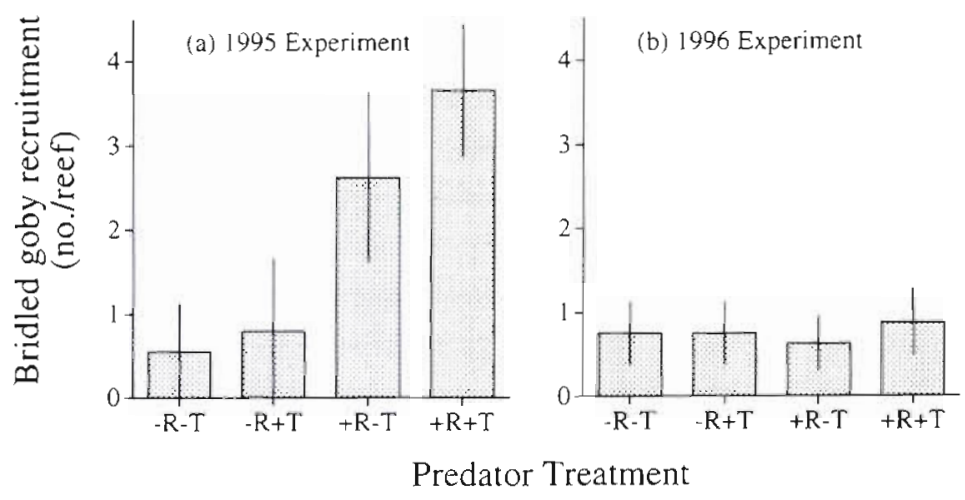

Fig. 4. Influences of resident and transient predators on recruitment of bridled gobies during 2 experiments. Treatments: $-\mathrm{R}-\mathrm{T}=$ no predators present; $-\mathrm{R}+\mathrm{T}=$ reefs exposed only to transient predators (uncaged, resident predators removed $)_{i}+\mathrm{R}-\mathrm{T}=$ reefs exposed only to resident predators (caged); and $+R+T=$ reefs exposed to both resident and transient predators (uncaged or partially caged). Data are backtransformed, adjusted least-squares means ( \pm the pooled SE) removing the influence of density of adult bridled gobies (see Fig. 3) in the 1995 experiment. For the 1996 experiment, data are unadjusted means ( $\pm 1 \mathrm{SE}$ ), since recruitment was unrelated to density of adults in this experiment. $n=6$ for each treatment in the 1995 experiment, except for the $+R+T$ treatment where $\mathrm{n}=12$; and $\mathrm{n}=8$ for each treatment in the 1996 experiment
Table 2. Summary of results of ANCOVA testing for effects of density of adult conspecifics, resident predators, transient predators, and interactions between these factors on recruitment of bridled gobies. Tests for main effects (effects of each class of predators and adult conspecifics) were made after eliminating the nonsignificant $(p>0.05)$ interaction terms involving the covariate (adult density) from the models (note $\mathrm{df}_{i}$ see 'Methods: statistical analyses' for rationale). Recruitment was transformed to square-root $(x+0.5)$ because this improved normality and created a more linear relationship between recruitment and adult density in the 1995 expenment. However, even after transformation, the data (in both experiments) were still not normally distributed owing to many zeros in the data sets. Consequently, the results presented here should be interpreted cautiously

\begin{tabular}{|lrrr|}
\hline Source & $\mathrm{df}$ & $F$ & $\mathrm{p}$ \\
\hline $\mathbf{1 9 9 5}$ experiment & & & \\
Adult conspecifics (Adults) & 1,25 & 4.57 & 0.042 \\
Resident predators (Residents) & 1,25 & 10.69 & 0.003 \\
Transient predators (Transients) & 1,25 & 0.49 & 0.49 \\
Residents $\times$ Transients & 1,25 & 0.10 & 0.75 \\
Adults $\times$ Residents & 1,23 & 0.05 & 0.82 \\
Adults $\times$ Transients & 1,24 & 0.13 & 0.73 \\
Adults $\times$ Residents $\times$ Transients & 1,22 & 0.38 & 0.55 \\
1996 experiment & & & \\
Adult conspecifics & 1,27 & 0.80 & 0.38 \\
Resident predators & 1,27 & 0.02 & 0.90 \\
Transient predators & 1,27 & 0.07 & 0.79 \\
Residents $\times$ Transients & 1,27 & 0.15 & 0.70 \\
Adults $\times$ Residents & 1,25 & 1.35 & 0.26 \\
Adults $\times$ Transients & 1,26 & 1.62 & 0.21 \\
Adults $\times$ Residents $\times$ Transients & 1,24 & 0.21 & 0.65 \\
& & & \\
\hline
\end{tabular}

predators was detected during the 1996 experiment (Fig. 4) but the power of the 1996 test was low. We had only a small chance of detecting an effect of predation of the magnitude observed in 1995 (power $=0.12$, given effect size $f=0.15, \mathrm{n}=15$, and setting $\mathrm{p}=$ 0.05 ), leading us to conclude that there probably is a generally positive effect of resident predators on bridled goby recruitment, but that recruitment was too low in 1996 to detect it. In neither of the 2 years were there any significant effects of transient predators, nor interactions between the 2 classes of predators, nor interactions between effects of predators and density of adults (Table 2).

\section{DISCUSSION}

\section{Influences of predators and conspecifics on recruitment of reef fishes}

Although predation is widely believed to be the ultimate cause of most mortality in reef fishes (Hixon 1991), and mortality is very 
high around the time of settlement (Doherty \& Sale 1985, Victor 1986, Sale \& Ferrell 1988, Booth 1991. Hixon \& Beets 1993, Levin 1993), it has proven difficult to unambiguously demonstrate that predators reduce recruitment of reef fishes. Several studies (Shulman 1984, Doherty \& Sale 1985, Hixon \& Beets 1993, Beets 1997. Steele 1997) have found evidence for predatorcaused reductions in recruitment, but many of these studies have confounded potential cage artifacts, or independent effects of habitat complexity (i.e. shelter availability), with effects of predators. However, a couple of recent studies (Beets 1997, Steele 1997) have demonstrated predator-induced reductions in recruitment of reef fishes, and Carr \& Hixon (1995) and Beukers \& Jones (1997) found effects of predators on survivorship of young reef fishes, although their studies did not examine natural recruitment.

Our comparison of recruitment on uncaged versus partially caged ('cage control') reefs suggested that artifacts of caging did not confound our tests for predatory effects. However, it is widely recognized that comparing partially caged areas with uncaged areas is not a foolproof test for artifacts of caging. Partial cages may not achieve their intended purpose of mimicking all of the effects of cages, while, at the same time, exposing prey populations to a risk of predation equal to that encountered in uncaged areas (Dayton \& Oliver 1980, Underwood \& Denley 1984, Steele 1996). We believe that the partial cages used in this study adequately mimicked the effects of exclosure cages, but we are less certain of their effects on risk of predation. Partial cages may alter risk of predation by attracting predators (e.g. Arntz 1977, Virnstein 1978) and/or influencing the ability of predators to capture prey in partially caged areas (Steele 1996). While we have no data on the potential effects of partial cages on predators in the Bahamas, Steele (1996) explored these sorts of effects using the same partial cages that were used in the present study with the blackeye goby. That work suggested that some predators may aggregate to partial cages (about twice as many Paralabrax spp. were seen near partially caged reefs compared to uncaged reefs, although this difference was not statistically significant). However, the efficacy of those predators appeared to be greatly reduced on partially caged reefs. Direct tests for cage artifacts in settled blackeye gobies (Steele 1996) indicate that this species is not affected by cage artifacts. This result, combined with the similar levels of recruitment in partially caged and uncaged reefs for the blackeye goby, leads us to interpret differences in recruitment between caged and uncaged reefs as being caused by predation and not as being an experimental artifact

Our results indicate that predators had strong effects on recruitment of both species that we studied, but these effects were opposite in direction: predators had a negative effect on the blackeye goby and a positive effect on the bridled goby (although this result was found in only 1 of 2 experiments). The bridled goby is the first reef-fish species that has shown a decrease in abundance in response to predator removal. Such positive effects of predators are quite common in other systems (reviewed in Sih et al. 1985), so there is reason to believe that future experiments will show them to occur in other species on coral reefs. The mechanism for the positive effect of resident predators on bridled gobies is uncertain. One possibility is that predators reduced the abundance of a superior competitor (e.g. keystone predation; Paine 1966). Another possibility is that removal of large piscivores allowed an increase in abundance of smaller generalist carnivores (such as the wrasses Halichoeres bivittatus and $H$. garnoti) whose abundance was not manipulated in the experiment. These smaller fishes have very catholic diets, and they may have preyed upon the recently settled gobies during our experiments.

The preceding paragraph highlights the point that in species-rich systems that include many generalist predators, it is difficult to pinpoint the mechanism(s) by which the abundance of 1 species is affected by others. Other workers have interpreted negative effects of predators as the direct result of predation (Carr \& Hixon 1995, Steele 1996, 1997, 1998, Beets 1997, Beukers \& Jones 1997). This is the simplest explanation of such results, and we offer this explanation as the most likely cause of reduced recruitment in the blackeye goby. However, in neither our study nor previous studies has there been direct evidence that predators reduced the abundance of prey solely by consuming them. Therefore, it is possible that some indirect effect of predators caused reduced recruitment of blackeye gobies, as well as causing increased recruitment in bridled gobies.

The effects of predators differed radically between the 2 species that we studied. That difference could be due to a general difference between a species-rich tropical system versus a less rich temperate system; or due to differences between our 2 prey species or differences among predator species that are unrelated to general differences between temperate and tropical systems. One hypothesis is that indirect effects of predators will be more common in tropical systems simply because of the increased number of species and greater complexity of the food webs. However, even within particular systems, great differences in the impacts of predators on reef fishes have been found. In a study on 3 tropical reef fishes, Carr \& Hixon (1995) found strong effects of resident predators on 2 species, but no effect on a third. Similarly, Beets (1997) found effects of a predatory reef fish on recruitment and 
abundance of some Caribbean reef fishes, but not on others. Also, Steele $(1997,1998)$ found strong impacts of predators on 1 temperate-reef species, but not another. The variation in impacts of predation among reef-fish species noted in this study and others is not simply an artifact of low statistical power to detect impacts of predators on some species but not others. Rather, there are real differences in the magnitude of predatory effects among prey species. This is not surprising, since risk of predation is determined by many complex and interacting factors, including the behavior and morphology of both predators and prey, which vary among species. For example, recently settled blackeye gobies may suffer greater losses to predators than bridled gobies do because blackeye gobies are more readily detectable, since they settle at a larger size and forage predominantly in the water column where they are quite visible. The very small bridled goby recruits remain on the substrate and move little while foraging on benthic invertebrates, making them difficult to detect. Furthermore, there were very few alternative prey on the patch reefs with blackeye gobies, which could have elevated the risk of predation for this species, whereas on the Bahamian reefs with bridled gobies, there were many alternative prey, including larger and more conspicuous species, which predators may have focused on, thus lowering the risk of predation for the bridled goby. Determining which factors cause variation in risk of predation among reeffish species should prove a profitable area of research because it may help us predict the relative importance of predation versus other post-settlement and pre-settlement processes in setting patterns of abundance.

For both blackeye and bridled gobies, there were temporal differences in predator impacts on recruitment. In 1 experiment, resident predators had a strong positive effect on recruitment of the bridled goby, but in a second experiment no effect was detectable. Likewise, predators reduced recruitment of the blackeye goby by as little as $37 \%$ in one experiment and by as much as $74 \%$ in another. Moreover, in an earlier study, Steele (1997) found no statistically significant influence of predators on recruitment of blackeye gobies (there was a nonsignificant $24 \%$ reduction in recruitment, measured using the same cage and reef design, at the same site as the present study). The differences in impacts of predators among time periods are not related to variation in predator abundance, since predators were rare $\left(0.17 \pm 0.05\right.$ reef $\left.^{-1}, \mathrm{n}=16\right)$ during the period when the greatest impact of predators was detected (the second month of the October-December experiment in this study), but common $(1.59 \pm 0.24$ reef $^{-1}, \mathrm{n}=36$ ) during the prior study, in which the smallest effects of predators were found. Recruitment, however, was extremely low (mean $=2.0 \mathrm{~m}^{-2}$; and many reefs received no recruitment) during the prior study, but higher (mean $=4.9$ to $36.2 \mathrm{~m}^{-2}$ ) during the present study. Low recruitment may decrease the likelihood of detecting any impacts on recruitment for statistical (e.g. see Sweatman 1985) or biological reasons (e.g. it may not be energetically profitable for predators to target rare prey types).

Like the impacts of predation, the influence of older conspecifics varied between the 2 species. Recruitment of bridled gobies appeared to be inhibited by adults, whereas there was no obvious effect of older conspecifics on the recruitment of blackeye gobies. Similar findings have been reported in previous experiments with these species (on reefs with natural predator communities present; Forrester 1995, Steele 1997), suggesting that they are consistent and reliable results. The full range of possible effects of older conspecifics has been found in other species, including negative effects (Sale 1976, Behrents 1987, Tupper \& Boutilier 1995), positive effects (Sweatman 1983, 1985, Jones 1987, Booth 1992, Schmitt \& Holbrook 1996, Steele 1997), and no detectable effects (Doherty 1983, Jones 1984, 1987, Levin 1993). One study on a tropical damselfish has even documented a hump-shaped relationship between recruitment and adult density (Schmitt \& Holbrook 1996) and such a relationship was suggested in 1 experiment with the blackeye goby (Fig. 1a). Indeed, one would expect that for all species of reef fishes, the relationship between recruitment and adult density must eventually become negative at high enough densities since resources should become limited. However, such high densities may only rarely or never occur naturally in some species.

We found no evidence for interactions between effects of predators and older conspecifics. Similarly, Steele (1997) found no evidence of such interactions between effects of predation and of older conspecifics in another species of reef fish, even though both factors had significant effects on recruitment. However, there is reason to believe that such interactions may sometimes occur; if, for example, recruitment is limited by available shelter (and older conspecifics pre-empt shelter space), then there might be a negative relationship between the density of conspecifics and recruitment in the presence of predators, but no such relationship in the absence of predators.

\section{Implications for regulation of local populations}

The influences of older conspecifics and predators on the 2 species that we studied clearly have the potential to modify patterns of spatial variation among reefs established by variable larval supply. Density-dependent recruitment in bridled gobies (Forrester 1995, this 
study) will serve to reduce variation in density among local populations and regulate them. Also, since the effects of predators vary temporally (this study) and spatially (Steele 1997, 1998), it is likely that predators will obscure patterns of abundance established at settlement. Therefore, on patch reefs, at the scales that we worked, post-dispersal processes have the potential to decouple patterns of abundance on reefs from patterns of larval supply to them. However, it is not clear whether this conclusion holds true at larger scales or in more connected habitats (i.e. large tracts of continuous reef). As Connell (1985) posited for intertidal barnacles, we predict that larval supply will be a primary determinant of reef-fish abundance and population structure when and where larval supply is low, but that the importance of larval supply will diminish as larval abundance increases. We make this prediction not only because density-dependent interactions with conspecifics should become stronger as density increases, but also because at higher densities it may become profitable for generalist predators to focus on species that were energetically unprofitable at low densities.

\section{Comparisons among species: generality?}

It is usually difficult to make comparisons among species because studies are done in different ways on different species. This study is among the first to compare the effects of predators and conspecifics (on any aspect of an organism's biology) between species and between systems, using a fairly standard experimental design. It is a first attempt, and so suffers some shortcomings, but nonetheless does offer some meaningful findings. Foremost among these, is that, even for very similar species (e.g. 2 small, benthic gobies in the same genus), the influences of biotic factors on a particular biological attribute (in this case, recruitment of young) may vary dramatically between species. Our task then is to understand the causes of variation among species, so that we can predict, say, the influences of predators and conspecific density on species that have not been well studied.

Even though the effects of predators and conspecifics varied widely between the 2 species that we studied, the abundance of both species was significantly influenced by post-settlement processes. Up until recently, based upon results of studies which have predominantly been done on damselfishes and wrasses, there was little evidence for strong post-settlement modification of abundance in reef fishes, which raises the question: are gobies somehow different from other reef fishes? We think not. Some recent studies on damselfishes (e.g. Carr \& Hixon 1995, Beuk- ers \& Jones 1997, Hixon \& Carr 1997, Schmitt \& Holbrook in press) and wrasses (e.g. Carr \& Hixon 1995. Tupper \& Boutilier 1995, 1997) have also demonstrated strong modification of abundance by post-settlement mortality (due to both predators and unidentified causes). Whether studies done on small, relatively sedentary species like gobies, damselfishes, and wrasses tell us much about larger, more mobile, and often economically more valuable reef-dwelling species, like groupers and snappers, remains to be seen.

Acknowledgements. We are grateful for excellent help in the field by many people, especially: S. Anderson, R. Buckley, B. Byrne, D. Canestro, M. Carr, B. Fredericks, M. Hixon, J. Malone, C. McKinny, Y. Springer, C. Tinus, T Trejo, and E. Tynes. The paper was improved by comments from C. Peterson and anonymous reviewers. The experiment at Lee Stocking Island would not have been possible without the help and generosity of $M$. Hixon and $M$. Carr, who allowed us to use their transplanted patch reefs, experimental cages, and field assistants, which were funded by their grants from NOAA-NURP (CMRC-92-46, 93-12, 94-15, and 95-3042) and NSF (OCE-9217163). Logistical support and hospitality were provided by the staffs of the Caribbean Marine Research Center and the Wrigley Institute for Environmental Studies. This work was also supported by a grant from the National Science Foundation to G. Forrester (OCE-96-18011). This is contribution number 201 from the Wrigley Institute for Environmental Studies.

\section{LITERATURE CITED}

Arntz WE (1977) Results and problems of an 'unsuccessful' benthos cage predation experiment (Western Baltic). ln: Keegan BF, Ceidigh PO, Boaden PJS (eds) Biology of benthic organisms. Pergamon Press, New York, p 31-44

Beets JP (1997) Effects of a predatory fish on the recruitment and abundance of Caribbean coral reef fishes. Mar Ecol Prog Ser 148:11-21

Behrents KC (1987) The influence of shelter availability on recruitment and early juvenile survivorship of Lythrypnus dalli Gilbert (Pisces: Gobiidae). J Exp Mar Biol Ecol 107: $45-59$

Beukers JS, Jones GP (1997) Habitat complexity modifies the impact of piscivores on a coral reef fish population. Oecologia 114:50-59

Booth DJ (1991) The effects of sampling frequency on estimates of recruitment of the domino damselfish Dascyllus albisella. J Exp Mar Biol Ecol 145:149-159

Booth DJ (1992) Larval settlement pattems and preferences by domino damselfish Dascyllus albisella Gill. J Exp Mar Biol Ecol 155:85-104

Carr MH (1989) Effects of macroalgal assemblages on the recruitment of temperate zone reef fishes. J Exp Mar Biol Ecol 126:59-76

Carr MH (1991) Habitat selection and recruitment of an assemblage of ternperate zone reef fishes. J Exp Mar Biol Ecol 146:113-1.37

Carr MH (1994) Effects of macroalgal dynamics on recruitment of a temperate reef fish. Ecology 75:1320-1333

Carr MH, Hixon MA (1995) Predation effects on early postsettlement survivorship of coral-reef fishes. Mar Ecol Prog Ser 124:31-42

Caselle JE, Warner RR (1996) Variability in recruitment of 
coral reef fishes: the importance of habitat at two spatual scales. Ecology 77:2488-2504

Cohen J (1988) Statistical power analysis for the behavioral sciences. Lawrence Erlbaum Associates, Hillsdale

Cole KS (1983) Protogynous hermaphroditism in a temperate zone territorial marine goby, Coryphopterus nicholsi. Copeia 1983:809-812

Cole KS, Shapiro DY (1992) Gonadal structure and population characteristics of the protogynous goby Coryphopterus glaucofraenum. Mar Biol 113:1-9

Connell JH (1985) The consequences of variation in initial settlement vs. post-settlement mortality in rocky intertidal communities. J Exp Mar Biol Ecol 93:11-45

Dayton PK, Oliver JS (1980) An evaluation of experimental analysis of population and community patterns in benthic marine environments. In: Tenore $\mathrm{K}$, Coull $\mathrm{BC}$ (eds) Marine benthic dynamics. Unuversity of South Carolina Press, Columbia, p 93-120

Doherty PJ (1981) Coral reef fishes: recruitment-limited assemblages? Proc 4 th Int Coral Reef Symp 2:465-470

Doherty PJ (1982) Some effects of density on the juveniles of two species of tropical, territorial damselfishes. J Exp Mar Biol Ecol 65:249-261

Doherty PJ (1983) Tropical territorial damselfishes: is density limited by aggression or recruitment? Ecology 64:176-190

Doherty PJ, Fowler A.J (1994) An empirical test of recruitment limitation in a coral reef fish. Science 263:935-939

Doherty PJ, Sale PF (1985) Predation on juvenile coral reef fishes: an exclusion experiment. Coral Reefs 4:225-234

Forrester GE (1995) Strong density-dependent survival and recruitment regulate the abundance of a coral reef fish. Oecologia 103:275-282

Hixon MA (1991) Predation as a process structuring coral reef fish communities. In: Sale PF (ed) The ecology of fish on coral reefs. Academic Press, San Diego, p 475-508

Hixon MA, Beets JP (1993) Predation, prey refuges, and the structure of coral-reef fish assemblages. Ecol Monogr 63: 77-101

Hixon MA, Carr MH (1997) Synergistic predation, density dependence, and population regulation in marine fish. Science 277:946-949

Jones GP (1984) Population ecology of the temperate reef fish Pseudolabrus celidotus Bloch \& Schneider (Pisces: Labridae) I. Factors influencing recruitment. J Exp Mar Biol Ecol 75:257-276

Jones CP (1987) Some interactions between residents and recruits in two coral reef fishes. J Exp Mar Biol Ecol 114: 169-182

Levin PS (1993) Habitat structure, conspecifıc presence and spatual variation in the recruitment of a temperate reef fish. Oecologia 94:176-185

Paine RT (1966) Food web complexity and species diversity. Am Vat 100:65-75

Sale PF (1976) The effect of territorial adult pomacentrid fishes on the recruitment and survival of juveniles on patches of coral rubble. J Exp Mar Biol Ecol 24:297-306

Sale PF, Douglas WA, Doherty PJ (1984) Choice of microhabitats by coral reef fishes at settlement. Coral Reefs 3:91-99

Sale PF, Ferrell DJ (1988) Early survivorship of juvenile coral reef fishes. Coral Reefs 7:117-124

Schmitt RJ, Holbrook SJ (1996) Local-scale patterns of larval settlement in a planktivorous damselfish-do they predict recruitment? Mar Freshwat Res 47:449-463

Schmitt RJ, Holbrook SJ (in press) Early mortality of juvenile damselfish: implications for assessing the processes that determine patterns of abundance. Ecology

Shulman MJ (1984) Resource limitation and recruitment patterns in a coral reef fish assemblage. J Exp Mar Biol Ecol $74: 85-109$

Shulman MJ (1985) Recruitment of coral reef fishes: effects of distribution of predators and shelter Ecology 66 : $1056-1066$

Shulman MJ, Ogden JC, Ebersole JP, McFarland WN, Miller SL, Wolf NG (1983) Prionty effects in the recruitment of juvenile coral reef fishes. Ecology 64:1508-1513

Sih A, Crowley P, McPeek M, Petranka J, Strohmeier K (1985) Piedation, competition, and prey communities: a review of field experiments. Annu Rev Ecol Syst 16:269-311

Sponaugle S, Cowan RK (1994) Larval durations and recruitment patterns of two Caribbean gobies (Gobiidae): contrasting early life histories in demersal spawners. Mar Biol 120:133-143

Steele MA (1996) Effects of predators on reef fishes: separating cage artifacts from effects of predation. J Exp Mar Biol Ecol 198:249-267

Steele MA (1997) The relative importance of processes affecting recruitment of two temperate reef fishes. Ecology 78 : $129-145$

Steele MA (1998) The relative importance of predation and competition in two reef fishes. Oecologia 115:222-232

Sweatman HPA (1983) Influnce of conspecifics on choice of settlement sites by larvae of two pomacentrid reef fishes (Dascyllus aruanus and D. reticulatus) on coral reefs. Mar Biol 75:225-229

Sweatman HPA (1985) The influence of adults of some coral reef fishes on larval recruitment. Ecol Monogr 55:469-485

Sweatman HPA, St. John J (1990) Effects of selective settlement and of aggression by residents on distribution of young recruits of two tropical damselfishes. Mar Biol 105: $247-252$

Tupper M, Bout1lier RG (1995) Effects of conspecific density on settlement, growth and post-settlement survival of a temperate reef fish. J Exp Mar Biol Ecol 191:209-222

Tupper M, Boutilier RG (1997) Effects of habitat on settlement, growth, predation risk and survival of a temperate reef fish. Mar Ecol Prog Ser 151:225-236

Underwood AJ, Denley EJ (1984) Paradigms, explanations, and generalizations in models for the structure of intertidal communities on rocky shores. In: Strong DR, Simberloff D, Abele LG. Thistle AB (eds) Ecological conmunities: conceptual issues and the evidence. Princeton University Press, Princeton, p 151-180

Underwood AJ, Petraitis PS (1994) Structure of intertidal assemblages in different locations: how can local processes be compared? In: Rickleffs RE, Schluter D (eds) Species diversity in ecological communities. University of Chicago Press, Chicago, p 39-51

Victor BC (1983) Recruitment and population dynamics of a coral reef fish. Science 219:419-420

Victor BC (1986) Larval settlement and juvenile mortality in a recruitment-limited coral reef fish population. Ecol Monogr 56:145-160

Virnstein RW (1978) Predator caging experiments in soft sediments: caution advised. In: Wiley ML (ed) Estuarine interactions. Academic Press, New York, p 261-273

Wiley JW (1973) Life history of the western North American goby, Coryphopterus nicholsii (Bean). Trans S Diego Soc Nat Hist 17:187-208

Wilkinson L, Hill M, Vang E (1992) SYSTAT: statistics, Version 5.2 edition. SYSTAT Inc., Evanston.

Submitted: September 3, 1997; Accepted: July 10, 1998

Proofs received from author(s): October 2, 1998 